\title{
Structures and Northward Propagation of the Quasi-Biweekly Oscillation in the Western North Pacific
}

\author{
KUIPING LI, YANG YANG, AND LIN FENG \\ Center for Ocean and Climate Research, First Institute of Oceanography, Ministry of Natural Resources, \\ and Laboratory for Regional Oceanography and Numerical Modeling, Qingdao National Laboratory for Marine Science \\ and Technology, Qingdao, China \\ WEIDONG YU \\ School of Atmospheric Sciences, Sun Yat-Sen University, Zhuhai Campus, and Southern Marine Science \\ and Engineering Guangdong Laboratory, Zhuhai, China \\ SHOUHUA LIU \\ National Marine Data and Information Service, Tianjin, China
}

(Manuscript received 7 October 2019, in final form 16 May 2020)

\begin{abstract}
This study investigates the northward-propagating quasi-biweekly oscillation (QBWO) in the western North Pacific by examining the composite meridional structures. Using newly released reanalysis and remote sensing data, the northward propagation is understood in terms of the meridional contrasts in the planetary boundary layer (PBL) moisture and the column-integrated moist static energy (MSE). The meridional contrast in the PBL moisture, with larger values north of the convection center, is predominantly attributed to the moisture convergence associated with barotropic vorticity anomalies. A secondary contribution comes from the meridional moisture advection, for which advections by mean and perturbation winds are almost equally important. The meridional contrast in the MSE tendency, due to the recharge in the front of convection and discharge in the rear of convection, is jointly contributed by the meridional and vertical MSE advections. The meridional MSE advection mainly depends on the moisture processes particularly in the PBL, and the vertical MSE advection largely results from the advection of the mean MSE by vertical velocity anomalies, wherein the upper-troposphere ascending motion related to the stratiform heating in the rear of the convection plays the major role. In addition, partial feedback from sea surface temperature (SST) anomalies is evaluated on the basis of MSE budget analysis. SST anomalies tend to enhance the surface turbulent heat fluxes ahead of the convention center and suppress them behind the convention center, thus positively contributing approximately $20 \%$ of the meridional contrast in the MSE tendency.
\end{abstract}

\section{Introduction}

Intraseasonal variability is a typical manifestation of intrinsic motions in the tropical atmosphere. Two separate modes, the 10-20-day quasi-biweekly oscillation (QBWO) and the 30-60-day intraseasonal oscillation (ISO), stand out in the power spectrum of many convection and circulation parameters (e.g., Madden and Julian 1971; Krishnamurti and Ardanuy 1980; Krishnamurti et al. 1985; Chen and Chen 1995; Li and Wang 2005). The identification of the ISO, as reported by T. Li et al. (2018), can be traced back

\footnotetext{
Corresponding author: Dr. Kuiping Li, likp@fio.org.cn
}

to a pioneering work by Xie et al. (1963). So far, extensive studies have been conducted on theories (e.g., Li 1985; Lau and Peng 1987; Wang 1988; Maloney and Hartmann 1998; Majda and Stechmann 2009), observations (e.g., Wang and Rui 1990; Hendon and Salby 1994; Fu et al. 2006; Benedict and Randall 2007; Adames and Kim 2016), simulations (e.g., Wang and Xie 1997; Maloney and Sobel 2004; Li et al. 2009; Hung et al. 2013; Cui et al. 2020), and climate impacts [see a brief summary in Zhang (2013)] related to the ISO. However, compared with the widely explored 30-60-day ISO, less attention has been paid to the QBWO.

The QBWO was first studied in the Indian monsoon region. Krishnamurti and Ardanuy (1980) and Krishnamurti 
et al. (1985) found that the break in monsoon rainfall coincided with the arrival of the ridge line in association with the QBWO. Chen and Chen (1993) analyzed the QBWO in 1979 and found that the QBWO exhibited a coherently westward-propagating double-cell structure and that the northern cell significantly modulated the Indian monsoon rainfall. In addition to the Indian monsoon, Chen and Chen (1995) noted that the onset of the South China Sea monsoon was also triggered by the westward-propagating low center of the QBWO. Besides, monsoon depressions in the Bay of Bengal are highly correlated with the westward-propagating QBWO from the South China Sea and western Pacific (Chen and Weng 1999). Recently, Kikuchi and Wang (2009) provided a global perspective of QBWO activity in terms of its initiation, movement, development, and dissipation. They reported that the QBWO tends to occur in monsoon regions and that the western North Pacific (WNP) possesses the largest variance during boreal summer. The QBWO, in the form of a coupled convection-circulation system, exhibits a dominant northwest movement in the WNP, significantly regulating weather and climate systems, such as extreme events (e.g., Liu et al. 2014; M. Gao et al. 2018), cyclone activity (e.g., Zhou et al. 2018; Shi et al. 2019), and monsoon progress (e.g., Chen and Chen 1995; Mao and Chan 2005; Jia and Yang 2013).

For dynamical frameworks, many studies have interpreted the QBWO as a gravest meridional mode equatorial Rossby wave in view of the structure and phase speed (Numaguti 1995; Chatterjee and Goswami 2004; Chen and Sui 2010). Using a simple model, Chatterjee and Goswami (2004) concluded that the unstable Rossby wave is mainly driven by the convective feedback of frictional boundary layer convergence, and the mean flow helps make the structure of the unstable wave more realistic. Chen and Sui (2010) showed that the QBWO in the WNP originated from the equatorial Rossby wave and propagated northward toward East Asia; additionally, their energetic analysis indicated that the wave was maintained through diabatic latent heating in the tropics. Given that the QBWO largely resembles an equatorial Rossby wave, the interpretation of the pronounced northward movement in the WNP is not clear enough. Kikuchi and Wang (2009) argued that the northward propagation of the QBWO can be understood in terms of the modulations of the mean monsoon circulation and convection on Rossby waves. As Wang and Xie (1996) and Xie and Wang (1996) noted, the easterly vertical shear in monsoon flow confines a Rossby wave in the lower troposphere, which further gains greater instability through the latent heating associated with the frictional moisture convergence in the planetary boundary layer (PBL). Meanwhile, the interaction between the mean easterly vertical shear and the convective anomalies induces a northward shift of the barotropic vorticity in the free atmosphere (Jiang et al. 2004); this shift then causes the PBL moisture to converge and results in the northward propagation of the convection. However, a systematic comparison between observations and the results of theoretical analysis has not been conducted for the QBWO in the WNP.

Moisture dynamics are a fundamental process in the convectively coupled Rossby waves associated with the QBWO. A phase-leading relationship between the PBL moisture and convection center has been proposed to precondition the QBWO propagation (Tao et al. 2009), which shares common features with the 30-60-day ISO (e.g., Fu et al. 2006; Adames and Wallace 2015). Many studies have already attempted to clarify the physical processes responsible for moisture anomalies of the ISO (e.g., Benedict and Randall 2007; Hsu and Li 2012; Hsu et al. 2014), although there still exist some discrepancies, particularly in the WNP. However, to the best of our knowledge, a complete moisture budget analysis is still lacking for the 10-20-day QBWO. Thus, it is imperative to understand the moisture dynamics of the QBWO, which is the aim of the present study.

Recently, a "moisture mode" theory has been widely accepted in the 30-60-day ISO framework (Raymond and Fuchs 2009; Maloney 2009; Adames and Kim 2016), where column-integrated moist static energy (MSE) is adopted as a prognostic variable. The MSE recharges (discharges) ahead of (behind) the convection, so that the propagation and maintenance of convection are governed by the physical processes regulating the MSE. The MSE budget analysis in the ISO has yielded many consensuses in recent literature. For example, horizontal and vertical advections are dominant terms in the MSE recharge/discharge during ISO evolution (Kim et al. 2014; Jiang 2017; Wang et al. 2017; Wang and Li 2020). Specifically, both terms tend to accumulate MSE anomalies in front of deep convection, and the higher MSE anomalies are distributed in the convective and stratiform heating regions, thus promoting the system propagation. In addition, some ocean feedback processes can be easily estimated in the MSE budget analysis. The coherent sea surface temperature (SST) anomalies during the ISO evolution contribute $10 \%-20 \%$ of the atmospheric MSE variability by modulating the surface latent and sensible heating (DeMott et al. 2016; Y. Gao et al. 2018). However, whether or to what extent the above results are true for the 10-20-day QBWO is unknown, because MSE budget analysis is still absent in QBWO research.

To identify the critical processes that modulate the northward propagation of the QBWO in the WNP, budget analyses on both PBL moisture and column MSE were conducted in the present study. To ensure the reliability of the results, the newly released fifth major global reanalysis produced by the European Centre for Medium-Range Weather Forecasts (ERA5; Hersbach 
and Dee 2016) was used because some previous reanalysis data failed to capture the moisture structure of the QBWO (Tao et al. 2009). The rest of the paper is organized as follows: The data and methods are described in section 2. Section 3 documents the structure of the QBWO with an emphasis on the PBL moisture. In section 4, we carry out the MSE budget analysis involving an evaluation of the SST feedback. The last section summarizes the analysis results and presents a short discussion.

\section{Data and methods}

\section{a. Data}

In this study, the parameters derived from ERA5 include 1) the three-dimensional velocity, specific humidity, temperature and geopotential at 25 pressure levels from 1000 to $150 \mathrm{hPa} ; 2$ ) the surface parameters of the air and dewpoint temperatures at $2 \mathrm{~m}$ and horizontal winds at $10 \mathrm{~m}$; and 3) the latent heat $(\mathrm{LH})$ and sensible heat ( $\mathrm{SH})$ fluxes at the sea surface, and the longwave and solar radiation at the sea surface and at the top of the atmosphere. In addition, satellite observations of precipitation and SST were used. The precipitation rate was derived from Tropical Rainfall Measuring Mission (TRMM) 3B42 3-hourly data (Kummerow et al. 2000), and a blended microwave and infrared product from the Group for High-Resolution Sea Surface Temperature (GHRSST; Martin et al. 2012) was used for SST. The blended SST product incorporates the advantages of microwave instruments and infrared instruments, which guarantees broad coverage and high resolution in the tropics. The original data, which had different spatial and temporal resolutions, were converted to $0.5^{\circ} \times 0.5^{\circ}$ (longitudelatitude) resolution at daily intervals spanning 2003-18. To isolate the signals associated with the QBWO, a 10-20-day bandpass filter was applied to the daily data.

\section{b. Moisture and MSE budget equations}

A moisture budget was conducted to examine the specific processes responsible for the moisture structure of the QBWO. Following Yanai et al. (1973), a perturbation form of the moisture tendency equation was written as

$\partial q^{\prime} / \partial t=-(u \partial q / \partial x)^{\prime}-(v \partial q / \partial y)^{\prime}-(\omega \partial q / \partial p)^{\prime}-\left(Q_{2} / L\right)^{\prime}$,

where $u$ is the zonal velocity, $v$ is the meridional velocity, $\omega$ is the $p$-vertical velocity, $q$ is the specific humidity, $Q_{2}$ is the apparent moisture sink, and $L$ is the latent heat constant. In the above equation, $-(u \partial q / \partial x)^{\prime}$ is the zonal moisture advection, $-(v \partial q / \partial y)^{\prime}$ denotes the meridional moisture advection, and $-(\omega \partial q / \partial p)^{\prime}$ indicates the vertical moisture advection; $-\left(Q_{2} / L\right)^{\prime}$ represents the moisture source or sink. The prime of each term means a projection at the 10-20-day time scale.

Following Neelin and Held (1987), the column-integrated MSE tendency equation associated with the QBWO was written as

$$
\begin{aligned}
\langle\partial m / \partial t\rangle^{\prime}= & -\langle u \partial m / \partial x\rangle^{\prime}-\langle v \partial m / \partial y\rangle^{\prime} \\
& -\langle\omega \partial m / \partial p\rangle^{\prime}+Q_{T}^{\prime}+Q_{R}^{\prime},
\end{aligned}
$$

where $m=L q+C_{p} T+g z$ is the expression of MSE, $C_{p}$ is the heat capacity of dry air at constant pressure, $g$ is the gravitational constant, and $z$ is the geopotential height. Also, $Q_{T}$ represents the surface turbulent fluxes (sum of surface $\mathrm{LH}$ and $\mathrm{SH}$ fluxes), and $Q_{R}$ indicates the radiative heating (sum of longwave and solar radiation fluxes absorbed by the atmosphere). Angle brackets denote a mass-weighted vertical integration from 1000 to $150 \mathrm{hPa}$. Other parameters are the same as those in Eq. (1).

\section{c. SST-induced turbulent heat fluxes}

Significant SST anomalies appear coherently with the evolution of the QBWO (Tao et al. 2009; Ye and $\mathrm{Wu} 2015$ ). These anomalies can alter the surface $\mathrm{LH}$ and SH fluxes by changing the vertical gradients of near-surface humidity and temperature, thereby providing feedback to the atmospheric MSE variability. To achieve a quantitative assessment of SST perturbation within the MSE budget, the state-of-the-art bulk flux algorithm version 3.0, developed by the Coupled Ocean-Atmosphere Response Experiment (COARE3.0; Fairall et al. 2003) was adopted. Four surface parameters (i.e., SST, air temperature, air humidity, and wind speed) determine the air-sea turbulent exchange in the algorithm. To obtain the effect of SST anomalies on the turbulent heat fluxes, two calculation steps were taken. In the first step, we calculated the LH and SH using the raw data of the above four parameters and marked the results as $\mathrm{LH}^{r}$ and $\mathrm{SH}^{r}$, respectively. In the second step, SST was substituted by a modified value, where the 10-20-day anomalies were subtracted from the raw SST data. The second results were marked as $\mathrm{LH}^{m}$ and $\mathrm{SH}^{m}$, respectively, which excluded the effect of the 10-20day SST anomalies. In this way, the SST-induced LH and $\mathrm{SH}$ anomalies (hereafter referred to as $\mathrm{LH}_{\text {sst }}$ and $\mathrm{SH}_{\mathrm{sst}}$ ) were easily estimated by comparing the results from the above two steps; that is, $\mathrm{LH}_{\mathrm{sst}}=\mathrm{LH}^{r}-\mathrm{LH}^{m}$ and $\mathrm{SH}_{\mathrm{sst}}=\mathrm{SH}^{r}-\mathrm{SH}^{m}$. 

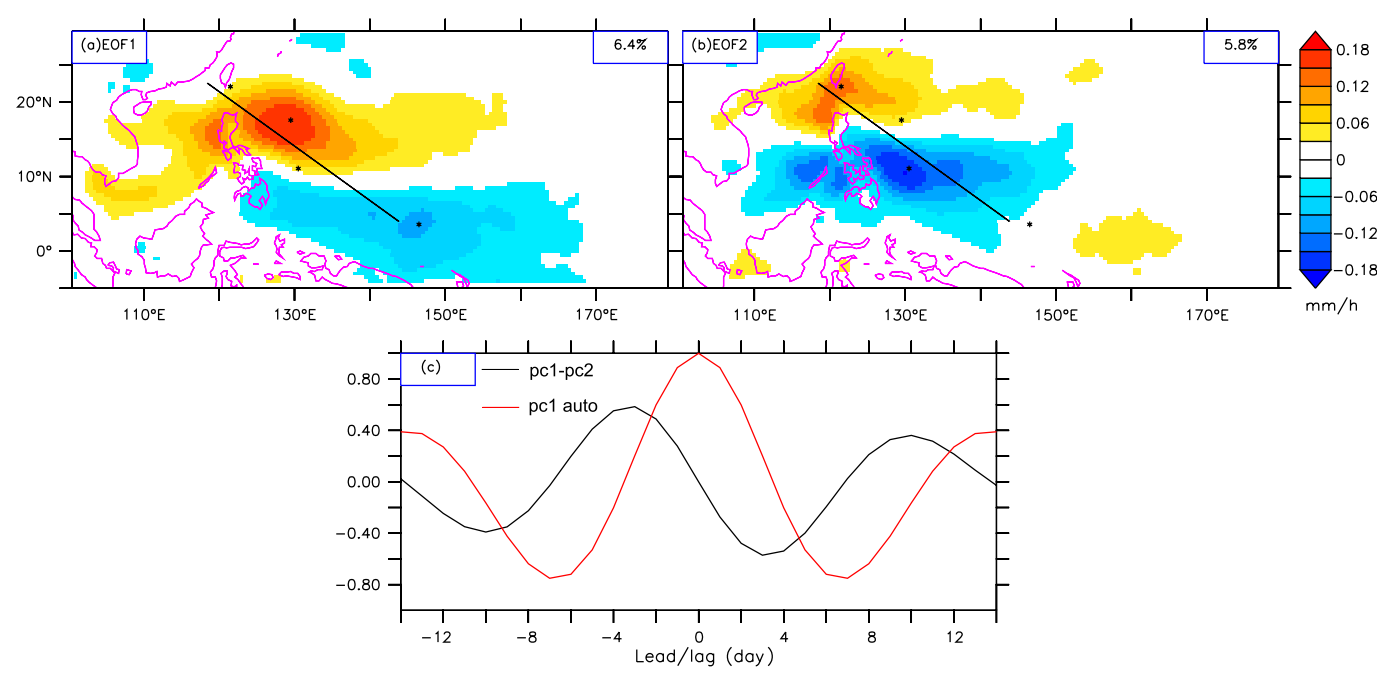

FIG. 1. Spatial patterns of (a) EOF1 and (b) EOF2 of the 10-20-day precipitation anomalies in JJAS for 2003-18. The numbers in the upper-right boxes show the relative contributions of each mode to the total variance. The black line in the panel indicates the fitted route of the QBWO. (c) Lead-lag correlation of PC1 and PC2 (black solid line), and the autocorrelation of PC1 (red solid line). Negative values of the abscissa represent days by which PC1 leads PC2/PC1.

\section{d. $Q B W O$ composite procedures}

The structures and mechanisms of the QBWO were diagnosed based on composite analysis, which was used for its mathematical simplicity and physical relevance to the governing process. The samples used for the composite were determined in terms of empirical orthogonal function (EOF) analysis. The EOF analysis was performed on the 10-20-day bandpass-filtered TRMM precipitation over the domain of $5^{\circ} \mathrm{S}-30^{\circ} \mathrm{N}$, $100^{\circ} \mathrm{E}-180^{\circ}$ for June-September (JJAS) during 2003-18. The principal components (PCs) of each EOF were normalized by one standard deviation, and the standard deviations were multiplied to the corresponding spatial modes. As shown in Fig. 1, the first two EOF modes explain similar variances, displaying quadrature phases of a northwest-propagating wave phenomenon. The general route of the propagating wave was linearly fitted based on the four anomalous centers in the two EOFs (each EOF has one positive and one negative center, as indicated in Figs. 1a and 1b). To reduce the effect of small-scale perturbations on the selection of anomalous centers, $10^{\circ} \times 10^{\circ}$ spatial running mean was first applied to EOF1 and EOF2.

The selection of strong QBWO events used for the subsequent composite analysis was based on the PC1 time series. Here, strong QBWO events were identified when PC1 exceeded 1.5 times the standard deviation. Accordingly, 46 strong events were identified in the summertime for the 16 -yr period. Then, these events were composited in reference to the days of the maximum PC1 (day 0), during which the strongest convection appeared in the WNP.

Because the present study mainly focused on northward propagation, the meridional sections of the QBWO were examined. First, each parameter was performed with a $20^{\circ}$ zonal average $\left(10^{\circ} \mathrm{W}\right.$ to $\left.10^{\circ} \mathrm{E}\right)$ along the fitted route of the QBWO. Then, TRMM precipitation was employed to search the meridional convection centers on days when pronounced northward-propagating convection appeared in the composite QBWO (day -7 to day +1 , as indicated in Figs. 2 and 3 ). Finally, latitudes corresponding to the maximum convection were selected as the reference points $\left(0^{\circ}\right)$ to produce the meridional composite for each parameter, wherein the distances with suffix S (N) represent the southward (northward) area of the QBWO convective center.

\section{Structures of the composite QBWO}

\section{a. Spatial-temporal evolutions and vertical structures}

According to the two leading EOFs of the TRMM precipitation anomalies in Figs. 1a and 1b, the dipole patterns in the northwest-southeast direction represent the northwestward movement of the QBWO. EOF1 illustrates the scenario when the rainfall anomalies become strongest in the WNP, while the dry anomalies begin to initiate near the equator. EOF2 exhibits evolutionary patterns a quarter cycle later, in which the rainfall anomalies decay rapidly, and dry anomalies develop significantly during the northward movement 


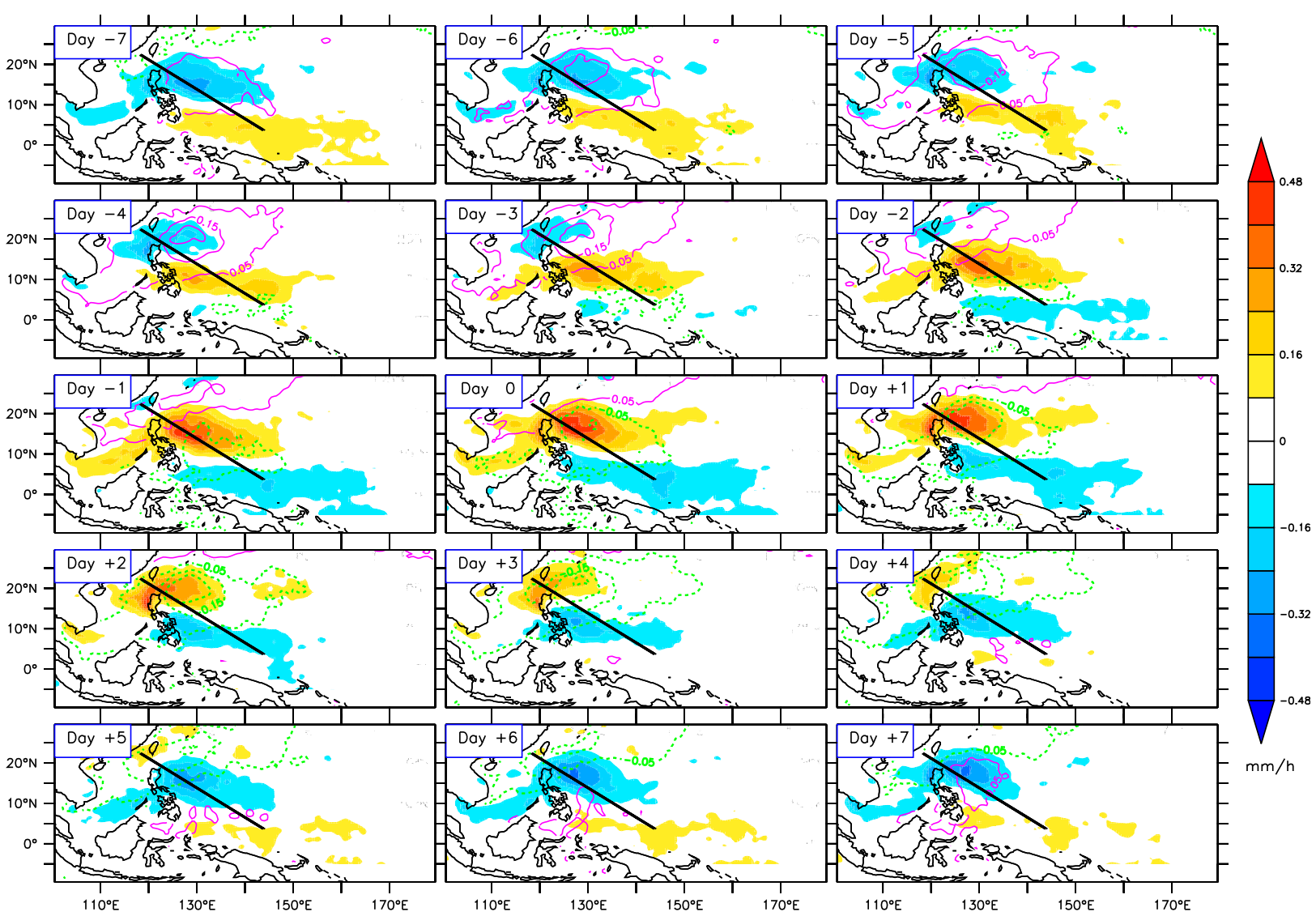

FIG. 2. Composite spatial-temporal evolutions of the precipitation anomalies (shading) and SST anomalies (contours) associated with the QBWO. Purple solid (green dashed) contours indicate positive (negative) anomalies with a contour interval of $0.1^{\circ} \mathrm{C}$ starting from $0.05^{\circ} \mathrm{C}\left(-0.05^{\circ} \mathrm{C}\right.$ ). Day 0 is a reference day when the PC1 values reach maxima for the selected events. The black lines in each panel indicate the fitted route of the QBWO.

process. The lead-lag correlations between the PC1 and PC2 time series are shown in Fig. 1c. It indicates that the maximum correlation occurs when PC1 leads (lags) PC2 by 3 days, as the correlation coefficient reaches approximately $0.6(-0.6)$. The autocorrelations of PC1 show that the minima occur when the lead/lag step is approximately 7 days. Thus, the oscillation period depicted by EOF1 and EOF2 should be roughly 2 weeks.

The composite life cycle of the QBWO is shown in Fig. 2. Generally, this northwestward-propagating system exhibits a meridional extension between $5^{\circ} \mathrm{S}$ and $25^{\circ} \mathrm{N}$ (approximately $3000 \mathrm{~km}$ ) and zonal elongation between $110^{\circ}$ and $170^{\circ} \mathrm{E}$ (approximately $6000 \mathrm{~km}$ ). On day -7 , strong dry anomalies dominate the WNP between $10^{\circ}$ and $20^{\circ} \mathrm{N}$, with the center east of the Philippines, while to the south, new convection initiates near the equator. The above spatial pattern displays the opposite phase for EOF1. In the subsequent days, the dry anomalies decay and the rainfall anomalies develop during the northwestward propagation. On day -3 , the decaying dry anomalies extend to the northernmost region around
Taiwan Island, and the developing convective anomalies arrive at $10^{\circ} \mathrm{N}$. The above pattern represents the opposite phase for EOF2. On day 0, the strongest convective anomalies dominate the WNP between $10^{\circ}$ and $20^{\circ} \mathrm{N}$, and

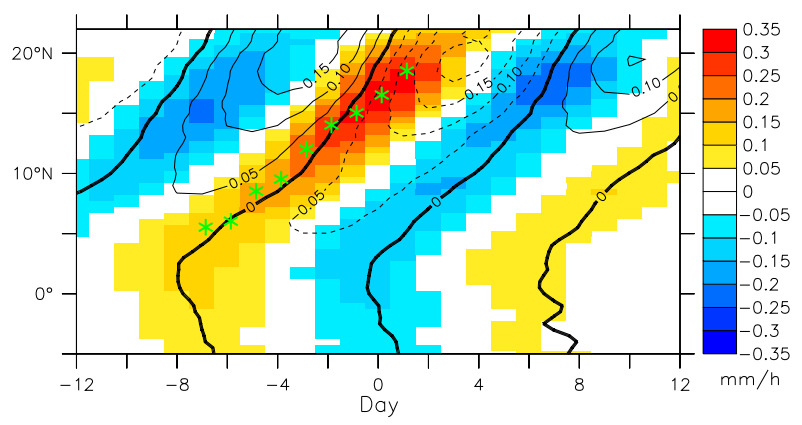

FIG. 3. Time-latitude evolutions of the precipitation anomalies (shading; $\mathrm{mm} \mathrm{h}^{-1}$ ) and SST anomalies (contours; ${ }^{\circ} \mathrm{C}$ ) along the fitted route of the QBWO. The result is based on a $20^{\circ}$ longitude average $\left(10^{\circ}\right.$ west to $10^{\circ}$ east of the black line in Fig. 2). The green asterisks indicate the meridional maxima that are used as the reference points for the composite structures of the QBWO. 
new dry anomalies initiate near the equator, which captures the main feature of EOF1. Thereafter, the second half of the QBWO life cycle begins in a similar manner as that described in the first half.

Air-sea interactions are active across phenomena of many time scales in the WNP, and it has been proposed that these interactions positively contribute to the maximum 30-60-day ISO center in the WNP during summer (Liu and Wang 2014). To help understand the role of airsea interactions in the evolution of the QBWO, the coherent SST evolution is plotted in Fig. 2. Accompanying atmospheric convection, the SST exhibits a clear oscillation in the WNP. The maximum SST anomalies are observed on days -4 to -3 , which is approximately a quarter of the cycle preceding the occurrence of maximum rainfall (day 0). This SST-convection relationship has been widely studied in the 30-60-day ISO (e.g., Weller and Anderson 1996; Lau and Sui 1997; Duvel et al. 2004; Halkides et al. 2015). It was concluded that surface heat fluxes associated with atmospheric convection are the major forces of SST variability, while ocean dynamics in the mixed layer also play a role. Detailed examination of SST variability within the QBWO cycle is temporarily beyond the scope of current work and will be carried out in near future. Meanwhile, the coherent SST evolution in the 30-60-day ISO is considered to significantly influence the development of atmospheric convection, through driving the PBL convergence (Hsu and Li 2012; Wang et al. 2018) and modifying the surface LH and SH fluxes (DeMott et al. 2016; Y. Gao et al. 2018). During the life cycle of the QBWO, the maximum positive (negative) SST anomalies are higher (lower) than $0.2^{\circ} \mathrm{C}\left(-0.3^{\circ} \mathrm{C}\right)$, exhibiting an amplitude similar to that of the 30-60-day ISO in the WNP (e.g., Ye and Wu 2015; Wang et al. 2018). Thus, it is inferred that ocean feedback also plays an important role in the evolution of the QBWO. In section 4, a quantitative assessment of the SST feedback through surface turbulent heat flux changes will be given on the basis of the MSE budget analysis.

The composite time-latitude section of the precipitation anomalies along the fitted QBWO route is shown in Fig. 3, in which nine meridional centers (green asterisks) are identified on those days when pronounced northwardpropagating convection occurs. The northward speed of the QBWO estimated by the above convection centers is approximately $1.7^{\circ}$ latitude per day. Then, by referencing the meridional convection centers, the meridional-vertical sections of the composite QBWO fields are constructed and are shown in Fig. 4. Associated with the deep convective system, a pronounced rising motion is observed in the troposphere. The vertical velocity exhibits a southward tilted structure with increasing height, and the maximum ascending flow appears at $300-400 \mathrm{hPa}$ in phase with the convection center. Below the maximum rising motion, pronounced cyclonic shear is mainly sustained by the zonal winds $\left(-\partial u^{\prime} / \partial y\right)$ and remarkable convergence is mostly induced by the meridional winds $\left(\partial v^{\prime} / \partial y\right)$. At the top of the troposphere, there tends to be anticyclonic circulation with meridional divergence. However, it is worth noting that the vorticity and divergence fields do not fully coincide with convection. The positive center of the vorticity is generally located at $2^{\circ}$ latitude north of the convection center. Due to the positive vorticity, a northward shift of the convergence in the PBL results from Ekman pumping. Similar to vertical velocity, a southward tilted structure is observed in the specific humidity field as the height increases. The maximum value appears in phase with the convection center at $500-600 \mathrm{hPa}$, which is consistent with satellite observations (Tao et al. 2009). However, the PBL moisture exhibits clear meridional asymmetry with regard to the convection center (i.e., the mean value in the north is much larger than that in the south), resulting in the asymmetry in atmospheric instability and causing the northward movement of the convection. Details on the governing processes responsible for the PBL moisture asymmetry will be addressed later in this paper. Above the PBL, striking positive temperature anomalies are induced by condensation heating, with the maximum anomaly locating at $300 \mathrm{hPa}$ in the convection center. In contrast, the geopotential field shows a significant meridional asymmetry relative to the convection center. Its negative center is nearly consistent with the positive vorticity center that appears approximately $2^{\circ}$ latitude north of the convection center. Generally, the MSE field largely resembles the specific humidity field, implying specific humidity is the leading contributor to the MSE variability.

\section{b. Analysis of the PBL moisture}

As documented previously, the meridional asymmetry in specific humidity may play an important role in guiding the northward propagation of the QBWO. To clearly illustrate its meridional asymmetry, the specific humidity field is decomposed into a symmetric and an asymmetric component with regard to the convection center, following Wang (1994) and Li (1997). The latitude-dependent specific humidity field, $q(y)$, where $y=0$ at the convection center, can be written as the sum of a symmetric component, $q_{\mathrm{sc}}(y)$, and an asymmetric component, $q_{\mathrm{ac}}(y)$, that is, $q(y)=$ $q_{\mathrm{sc}}(y)+q_{\mathrm{ac}}(y)$. Here, at any given point $\left(y_{0}\right), q_{\mathrm{sc}}\left(y_{0}\right)=$ $\left[q\left(y_{0}\right)+q\left(-y_{0}\right)\right] / 2$, and $q_{\mathrm{ac}}\left(y_{0}\right)=\left[q\left(y_{0}\right)-q\left(-y_{0}\right)\right] / 2$. Because $q_{\mathrm{sc}}(y)$ does not favor either side of the convection center, revealing $q_{\mathrm{ac}}(y)$ may provide vital evidence for explaining the meridional shift of the QBWO convection.

In the PBL, $q_{\mathrm{ac}}(y)$ shows striking positive (negative) values ahead of (behind) the convection center, while an opposite pattern appears in the middle troposphere 
(a)p-velocity

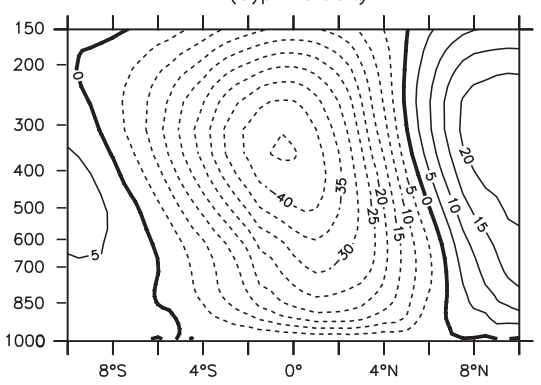

(d)relative vorticity

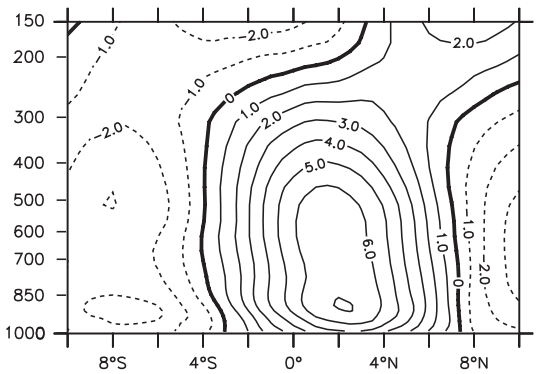

(g)temperature

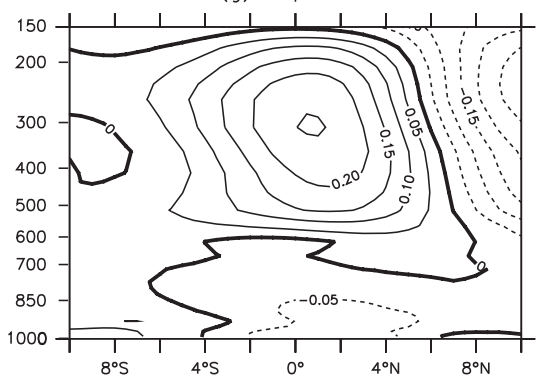

(b) zonal wind

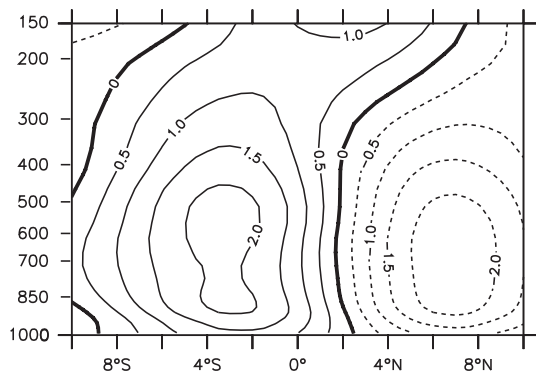

(e)divergence

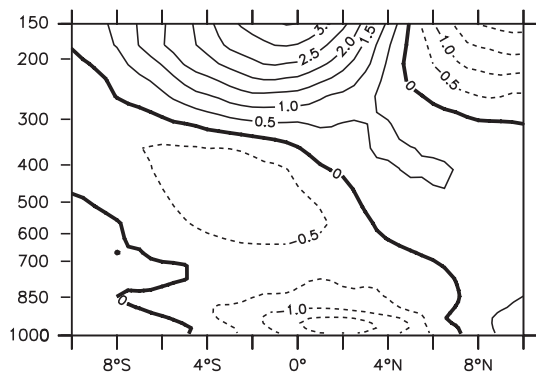

(h)geopotential

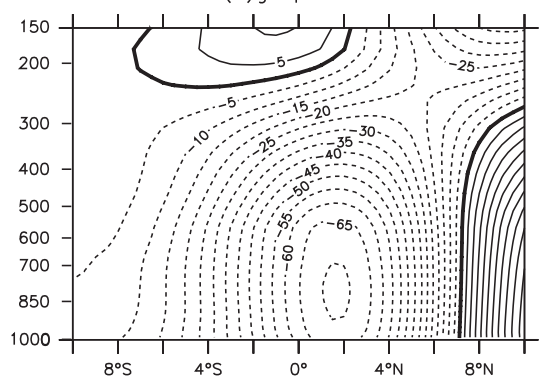

(c)meridionol wind

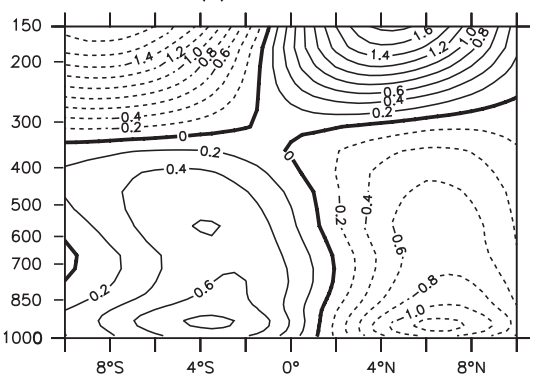

(f) specific humidity

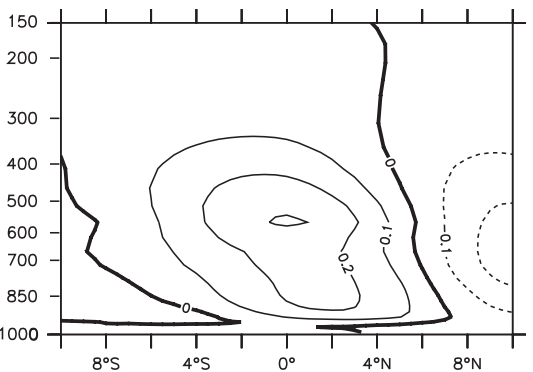

(i) mse

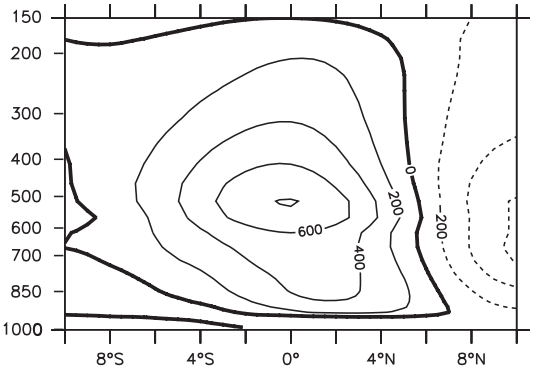

FIG. 4. Meridional-vertical sections of the composite QBWO fields: (a) vertical velocity $\left(10^{-3} \mathrm{~Pa} \mathrm{~s}^{-1}\right)$, (b) zonal wind (m s $\left.{ }^{-1}\right)$, (c) meridional wind $\left(\mathrm{m} \mathrm{s}^{-1}\right)$, (d) relative vorticity $\left(10^{-6} \mathrm{~s}^{-1}\right)$, (e) divergence $\left(10^{-6} \mathrm{~s}^{-1}\right)$, (f) specific humidity $\left(\mathrm{g} \mathrm{kg}^{-1}\right)$, (g) temperature $(\mathrm{K})$, (h) geopotential $\left(\mathrm{m}^{2} \mathrm{~s}^{-2}\right)$, and (i) moist static energy $\left(\mathrm{m}^{2} \mathrm{~s}^{-2}\right)$. The horizontal axis is the meridional distance relative to the QBWO convective center, with the suffix $\mathrm{S}(\mathrm{N})$ meaning southward (northward). The vertical axis is the pressure (hPa).

(Fig. 5a). This would induce greater atmospheric instability ahead of the center and cause the northward movement of convection. To understand the physical processes responsible for the asymmetric moisture structure, a moisture budget analysis is conducted in the PBL (1000-850 Pa) based on Eq. (1). Each term in the equation, in a similar way, is decomposed into a symmetric and an asymmetric component. As indicated in Fig. 6a, the meridional contrast in the moisture field is primarily caused by the vertical moisture advection, which exhibits pronounced positive (negative) values to the north (south) of the convection center. The meridional moisture advection, although its magnitude is secondary, also exerts a positive contribution to the meridional moisture contrast. Generally, the meridional patterns of the zonal moisture advection and moisture source/sink terms do not match the observed meridional moisture contrast.
When considering the continuity equation, the vertical moisture advection may be further expressed as $-(\omega \partial q / \partial p)^{\prime}=-(\partial \omega q / \partial p)^{\prime}-(q \cdot \operatorname{div} \mathbf{V})^{\prime}$, where $\operatorname{div} \mathbf{V}$ is the divergence of horizontal winds. For the right-handside terms, $-(\partial \omega q / \partial p)^{\prime}$ represents the vertical moisture flux, and $-(q \cdot \operatorname{div} \mathbf{V})^{\prime}$ indicates the moisture convergence, wherein the latter term plays the dominant role in contributing to the total vertical advection term (Fig. 6b).

The above budget analysis reveals that moisture convergence [i.e., $-(q \cdot \operatorname{div} \mathbf{V})^{\prime}$ ] and meridional moisture advection [i.e., $\left.-(v \partial q / \partial y)^{\prime}\right]$ are the leading terms responsible for the meridional moisture asymmetry in the PBL. Furthermore, the interactions between the QBWO perturbations and the mean states are addressed to clearly elucidate the underlying physical processes. Here, the mean state is marked by an overbar to represent the low-frequency component with periods longer than 60 days (to exclude synoptic disturbances, the 10-20-day QBWO and the 30-60-day ISO). 
(a)specific humidity

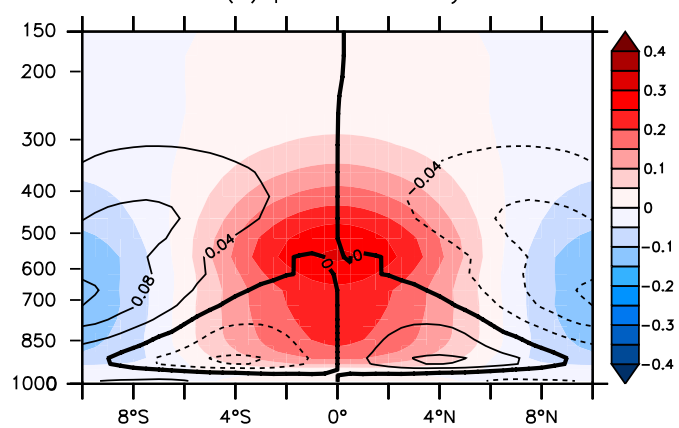

(b)p-velocity

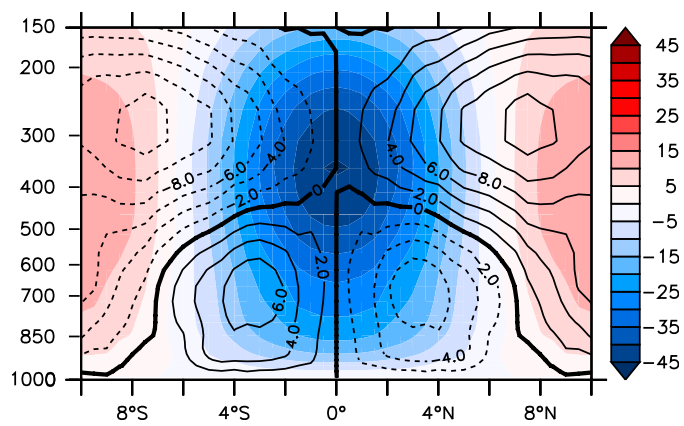

FIG. 5. Meridional-vertical sections of the symmetric (shading) and asymmetric (contours) components of the (a) specific humidity $\left(\mathrm{g} \mathrm{kg}^{-1}\right)$ and (b) vertical velocity $\left(10^{-3} \mathrm{~Pa} \mathrm{~s}^{-1}\right)$ fields. The coordinate axes are the same as in Fig. 4.

As seen from Figs. $6 \mathrm{~b}$ and $6 \mathrm{c}$, the moisture convergence is primarily due to the interaction between the QBWO divergence anomalies and the mean moisture (i.e., $-\bar{q} \cdot \operatorname{div} \mathbf{V}^{\prime}$ ). For meridional moisture advection, advections by mean and perturbation winds $\left(-\bar{v} \partial q^{\prime} / \partial y\right.$ and $\left.-v^{\prime} \partial \bar{q} / \partial y\right)$ show similar partial contributions, and the sum of both advective terms accounts for more than half of the total advection term.

The aforementioned three terms, involving the interactions between perturbations and mean states, have already been emphasized regarding the northwardpropagating 30-60-day ISO, and their physical interpretations can be adopted here for the QBWO. The first term (i.e., $-\bar{q} \cdot \operatorname{div} \mathbf{V}^{\prime}$ ) obviously results from the meridional asymmetry in the PBL convergence (Fig. 4e). Dynamically, in the presence of easterly shear of the mean zonal wind (Jiang et al. 2004) or northerly shear of the mean meridional wind (Bellon and Sobel 2008), barotropic vorticity anomalies may be generated north of the convection center (Fig. 4d). In this situation, the north-of-convection free-atmosphere barotropic vorticity anomalies drive the PBL convergence and cause meridional asymmetry. It is suggested that both shear environments may act on the QBWO because mean easterly shear and mean northerly shear are observed in the WNP during summer (Figs. 7a,b). Regarding the two advective terms, moisture advection by mean meridional wind $\left(-\bar{v} \partial q^{\prime} / \partial y\right)$ depicts the steering effect of a mean southerly in the WNP (Fig. 7a), and moisture advection by anomalous wind $\left(-v^{\prime} \partial \bar{q} / \partial y\right)$ reflects the meridional contrast in anomalous wind (southerly to the south and northerly to the north of the convection center, Fig. $4 \mathrm{c}$ ) in the presence of a mean northward moisture gradient (Fig. 7c). For a quantitative estimation, the ratio $-\bar{q} \cdot \operatorname{div} \mathbf{V}^{\prime}:-\bar{v} \partial q^{\prime} / \partial y:-v^{\prime} \partial \bar{q} / \partial y$ is approximately $8: 1: 1$, if we simply take their averages between $0^{\circ}$ and $10^{\circ} \mathrm{N}$. As a result, the moistening processes associated with these terms precondition the northward propagation of the QBWO convective system.

\section{MSE budget analysis of the QBWO}

\section{a. Column-integrated MSE budget}

Recent studies arising from the "moisture mode" theory have revealed many fundamental aspects associated with the 30-60-day ISO. The essential prognostic

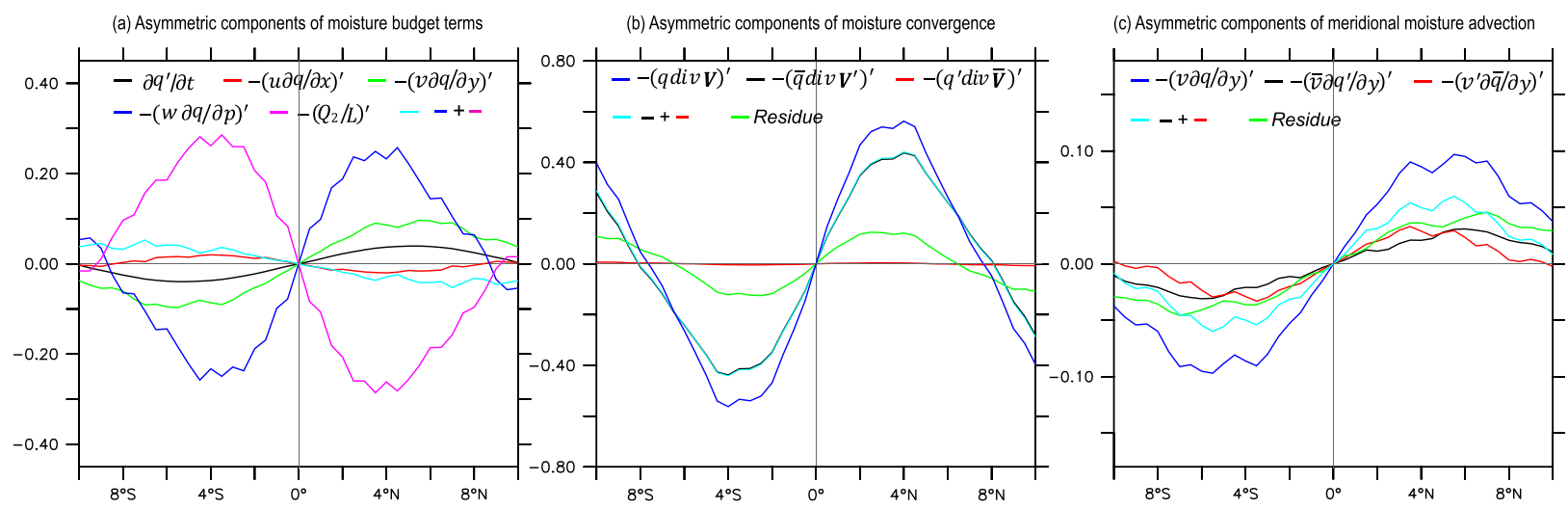

FIG. 6. Asymmetric components of (a) moisture budget terms in Eq. (1), (b) decomposed moisture convergence, and (c) decomposed meridional moisture advection in the PBL of $1000-850 \mathrm{hPa}$. The unit is $\mathrm{g} \mathrm{kg}^{-1} \mathrm{day}^{-1}$. See the legends in each panel for details. 

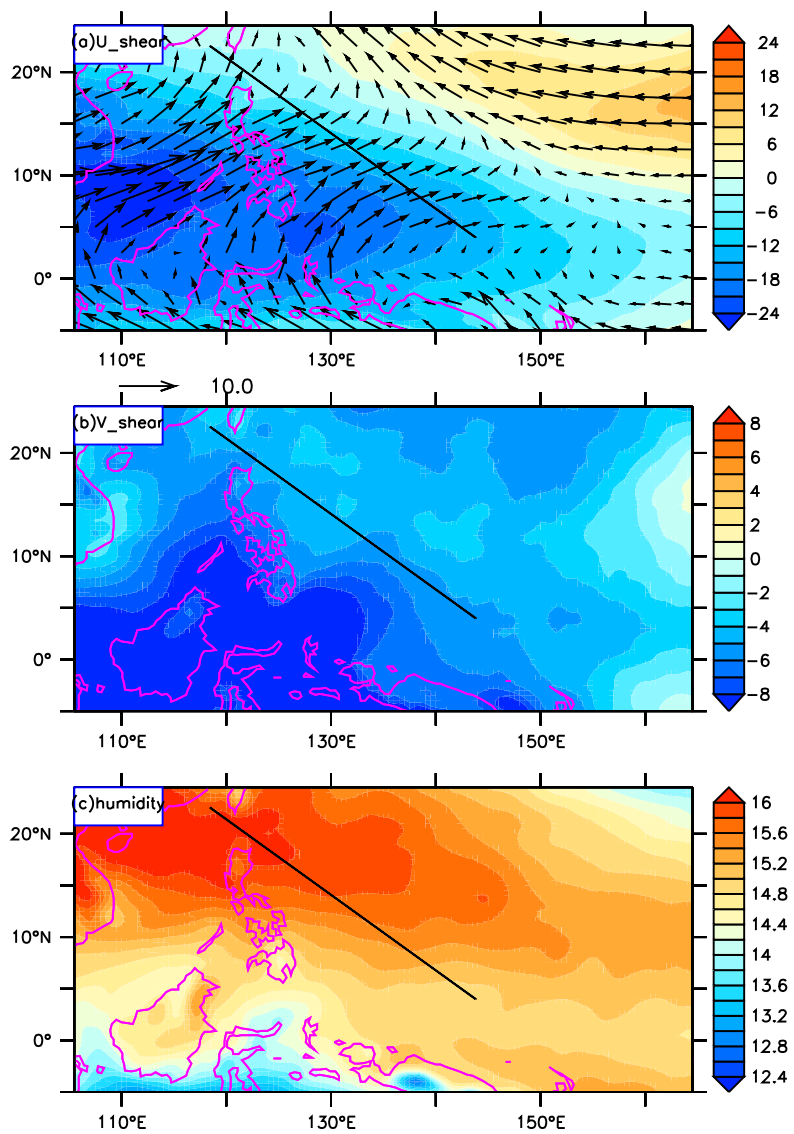

FIG. 7. JJAS mean (a) vertical shear of zonal wind (U200-U850; shading; $\mathrm{m} \mathrm{s}^{-1}$ ) and PBL wind (vectors; $\mathrm{m} \mathrm{s}^{-1}$ ), (b) vertical shear of meridional wind (V200-V850; $\mathrm{m} \mathrm{s}^{-1}$ ), and (c) PBL specific humidity $\left(\mathrm{g} \mathrm{kg}^{-1}\right)$. The black line indicates the fitted route of the QBWO.

variable, atmospheric column-integrated MSE, recharges (discharges) in the front (rear) of the convection, thereby regulating the propagation of the convective system. Based on the diagnostic equation of MSE, the roles of surface turbulent fluxes, radiative heating, and advective terms are easily quantified in the ISO evolution. In the last section, we found that the 10-20-day QBWO shares many common features with the ISO. Now, we describe what we learn from the MSE budget analysis regarding the northward-propagating QBWO.

Figure 8a illustrates the coherent evolution between the QBWO precipitation anomalies and the MSE tendency anomalies. There is a positive (negative) MSE tendency accompanied by an enhancement (reduction) of precipitation to the north (south) of the convection center, which means that the MSE recharge/discharge also governs the development and propagation of the QBWO convective system. Since the sum of the righthand-side terms in Eq. (2) (red line) is quite close to the MSE tendency (black line), further examination is carried

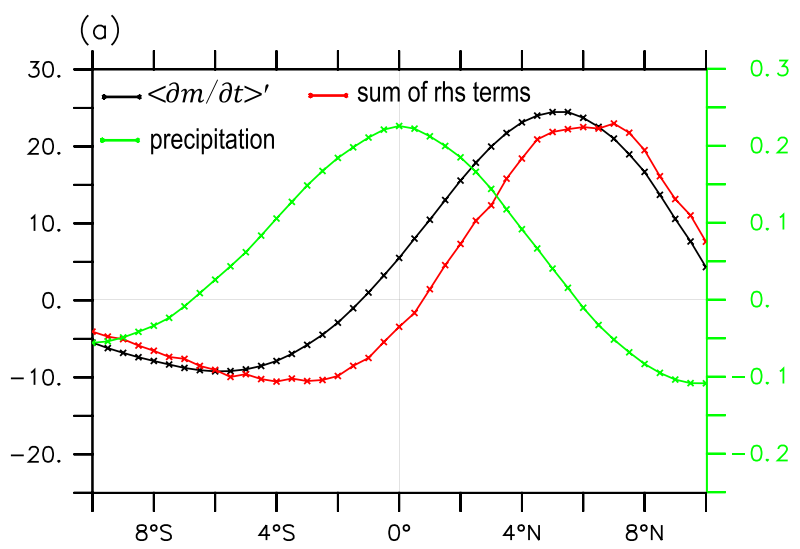

(b)

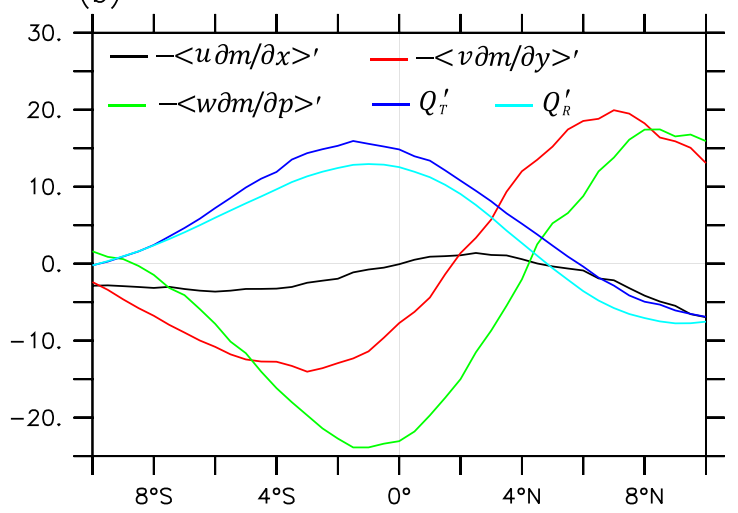

(c)

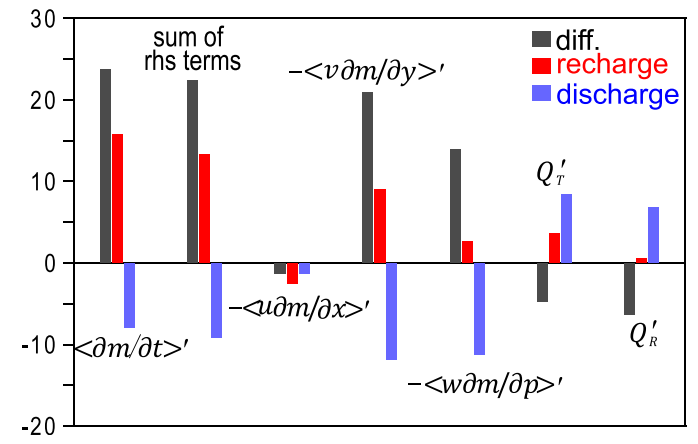

FIG. 8. (a),(b) Meridional distributions of the MSE budget terms $\left(\mathrm{W} \mathrm{m}^{-2}\right)$ in Eq. (2). The green line in (a) is the precipitation anomaly $\left(\mathrm{mm} \mathrm{h}^{-1}\right)$ that refers to the right $y$ axis. (c) Mean values in the MSE recharge area $\left(0.5^{\circ}-10^{\circ} \mathrm{N}\right.$; red bars), discharge area $\left(0.5^{\circ}-\right.$ $10^{\circ} \mathrm{S}$; blue bars), and their difference (black bars) for each budget term $\left(\mathrm{W} \mathrm{m}^{-2}\right)$. See the legends in each panel for details.

out to explore the individual contributions from different terms to the distinct meridional MSE contrast.

The meridional sections of each MSE budget term are given in Fig. 8b. The vertical advection term has the largest fluctuation, showing positive values north of $4^{\circ} \mathrm{N}$ and a minimum near the convection center. The meridional advection slightly lags behind the vertical advection, which switches sign at approximately $2^{\circ}$ latitude 
TABLE 1. Differences between the recharge and discharge area in meridional MSE advection $\left(\mathrm{W} \mathrm{m}^{-2}\right)$, as well as the percentage contributions from the moisture, temperature, and geopotential.

\begin{tabular}{lccc}
\hline \hline$-\langle v \partial m / \partial y\rangle^{\prime}$ & $-\langle v \partial L q / \partial y\rangle^{\prime}$ & $-\left\langle v \partial C_{p} T / \partial y\right\rangle^{\prime}$ & $-\langle v \partial z / \partial y\rangle^{\prime}$ \\
\hline 20.94 & $20.31(97 \%)$ & $3.5(17 \%)$ & $-2.87(-14 \%)$
\end{tabular}

north of the convection center. Obviously, the above two terms positively contribute to the striking MSE recharge-discharge contrast between the front and rear of convection. On the other hand, the surface turbulent flux and radiative heating exhibit a similar meridional pattern, which becomes positive at approximately $4^{\circ}-6^{\circ} \mathrm{N}$ and reaches maximum close to the convection center. These two terms display a nearly symmetric structure relative to the convection center; in this regard, neither term produces a striking contrast in MSE between the two sides of convection center. Generally, the zonal advection is negligible compared with the other terms.

To achieve a quantitative assessment, the averages in the MSE recharge area $\left(0.5^{\circ}-10^{\circ} \mathrm{N}\right)$ and discharge area $\left(0.5^{\circ}-10^{\circ} \mathrm{S}\right)$, as well as their difference, are further calculated for each budget term (Fig. 8c). The result indicates that the MSE recharge in front of the convection (red bars) is primarily attributed to the meridional advection, while the surface turbulent flux and vertical advection are secondary. For the MSE discharge at the rear of the convection (blue bars), the meridional and vertical advections are almost equally important. In view of the distinct contrast between the front and rear of the convection (black bars), the meridional and vertical advections are the top two leading terms, while other terms do not have positive contributions. In other words, the meridional and vertical advections dominantly govern the MSE recharge/discharge associated with the evolution of the QBWO convective system.

To better understand the meridional MSE advection, a linear decomposition is conducted with the three involved components (i.e., specific humidity, air temperature, and geopotential height). It is found that the recharge-discharge contrast in meridional advection basically depends on the moisture component (Table 1). Moreover, the meridionalvertical section in Fig. 9 demonstrates that the meridional moisture advection mainly comes from the PBL below $850 \mathrm{hPa}$. One may revisit the analysis in section 3 to help understand the PBL meridional moisture advection, and duplicate discussion is avoided here.

In a recent study by Wang et al. (2017), vertical MSE advection was analyzed in detail for the 30-60-day ISO. They emphasized the role of advection of the mean MSE by vertical velocity anomalies in the eastward

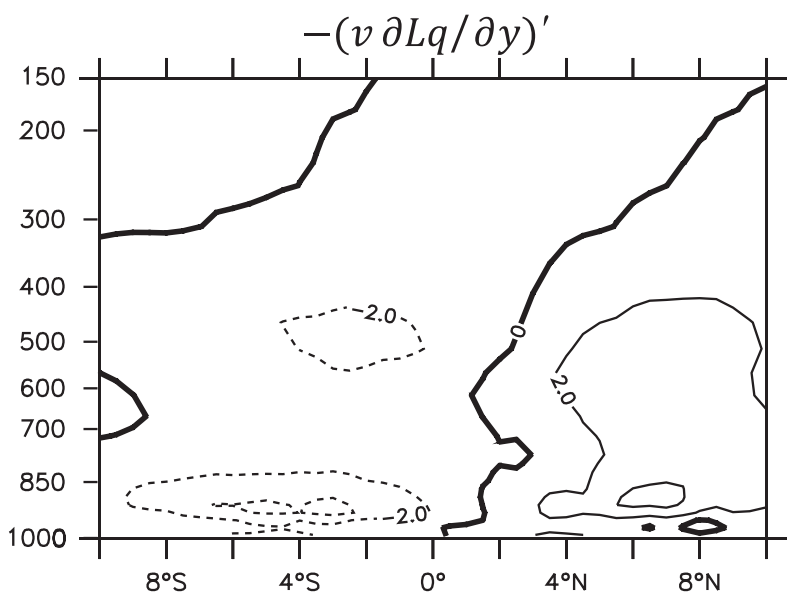

FIG. 9. Meridional-vertical section of the meridional MSE advection associated with moisture $\left(10^{-3} \mathrm{~m}^{2} \mathrm{~s}^{-3}\right)$, i.e., $-(v \partial L q / \partial y)^{\prime}$. The coordinate axes are as in Fig. 4.

propagation of the ISO. To the east of the ISO convection, ascending (descending) anomalies appear in the lower (upper) troposphere, while to the west the opposite occurs. Because the mean MSE is minimized in the midtroposphere, such a distribution of vertical velocity anomalies would induce positive (negative) MSE advection to the east (west), promoting the eastward propagation of the ISO. As the first guess, the above mechanism would also operate in the northward-propagating QBWO. For one reason, the advection of the mean MSE by vertical velocity anomalies explains almost all of the total vertical advection terms (Table 2), which is the same as that of the 30-60-day ISO; for the other, the vertical velocity anomalies exhibit a similar asymmetric structure in the meridional direction (ascending in the lower troposphere and descending in the upper troposphere to the north of the convection center, and the opposite appears to the south, Fig. 5b), much like that in the zonal direction for the 30-60day ISO. During the northward movement of the QBWO, the meridional asymmetry of vertical velocity in the upper troposphere is probably due to stratiform heating at the rear of convection and that in the lower troposphere may be largely associated with shallow convective processes in front of deep convection. Furthermore, the vertical profile of $-\left(\omega^{\prime} \partial \bar{m} / \partial p^{\prime}\right)$ in Fig. 10a confirms the essential role of stratiform heating in the QBWO, because the striking

TABLE 2. Differences between the recharge and discharge area in vertical MSE advection $\left(\mathrm{W} \mathrm{m}^{-2}\right)$, as well as the percentage contribution from $-\left\langle\omega^{\prime} \partial \bar{m} / \partial p\right\rangle^{\prime}$ (an overbar represents the lowfrequency component with a period longer than 60 days)

\begin{tabular}{lcc}
\hline \hline$-\left\langle\omega^{\prime} \partial m / \partial p\right\rangle^{\prime}$ & $-\left\langle\omega^{\prime} \partial \bar{m} / \partial p\right\rangle^{\prime}$ & Residual \\
\hline 13.6 & $13.3(98 \%)$ & $0.3(2 \%)$ \\
\hline
\end{tabular}


(a) $-\left(w^{\prime} \partial \bar{m} / \partial p\right)^{\prime}$

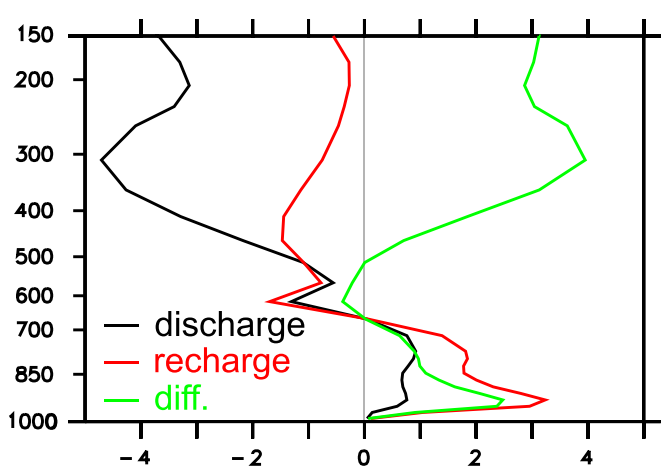

(b) $w^{\prime} \& \bar{m}$

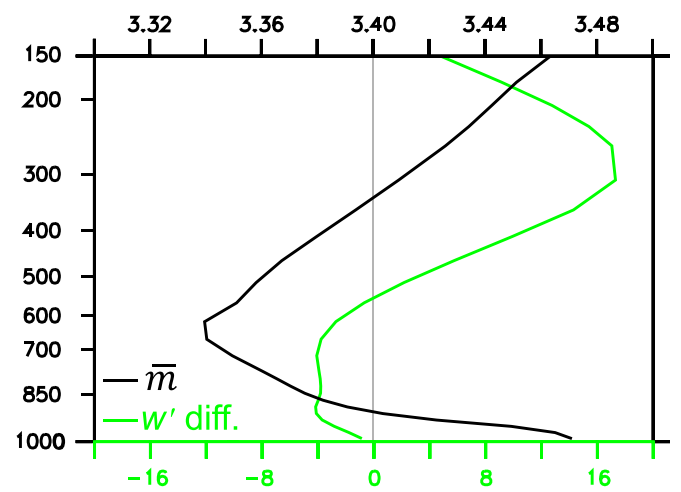

FIG. 10. (a) Profiles of vertical MSE advection in the form of $\omega^{\prime}$ acting on $\partial \bar{m} / \partial p$, i.e., $-\left(\omega^{\prime} \partial \bar{m} / \partial p\right)^{\prime}$. The red, black, and green lines represent the meridional mean in the recharge area $\left(0.5^{\circ}-10^{\circ} \mathrm{N}\right)$, discharge area $\left(0.5^{\circ}-10^{\circ} \mathrm{S}\right)$, and their differences $\left(10^{-3} \mathrm{~m}^{2} \mathrm{~s}^{-3}\right)$, respectively. (b) The $\omega^{\prime}$ differences between recharge and discharge area (green line; $10^{-3} \mathrm{~Pa} \mathrm{~s}^{-1}$ ) and the JJAS mean MSE in $0^{\circ}-20^{\circ} \mathrm{N}, 110^{\circ}-150^{\circ} \mathrm{E}$ (black line; $10^{5} \mathrm{~m}^{2} \mathrm{~s}^{-2}$ ).

difference between the recharge and discharge area (green line) mainly comes from the upper troposphere, that is, the interaction of relatively descending anomalies with an upward gradient of the mean MSE (Fig. 10b). In this way, the vertical MSE advection acts critically in the northwardpropagating QBWO, working similarly with the eastwardpropagating 30-60-day ISO (Wang et al. 2017).

\section{b. Role of SST feedback through surface turbulent fluxes}

The MSE budget analysis showed that the surface turbulent heat fluxes do not positively contribute to the MSE recharge-discharge contrast between the front and the rear of the convection. Considering that the $\mathrm{LH}$ and $\mathrm{SH}$ fluxes describe the gross effect of interactively varying oceanic and atmospheric processes, the above fact does not refute a potentially positive feedback from the significant SST anomalies involved in the life cycle of the QBWO (Fig. 2). Next, the SST-induced turbulent heat fluxes are evaluated, and their partial contribution to the QBWO MSE variability is estimated.

As mentioned previously, four surface parameters (i.e., SST, air temperature, air humidity, and wind speed) determine the air-sea turbulent exchange in the COARE3.0 algorithm. First, their meridional sections associated with the composite QBWO are examined in Fig. 11. It shows that positive (negative) SST anomalies are located ahead of (behind) the convection center, with a maximum appearing at $8^{\circ} \mathrm{N}$. This result implies that, in cases where the SST is the only consideration, positive (negative) turbulent
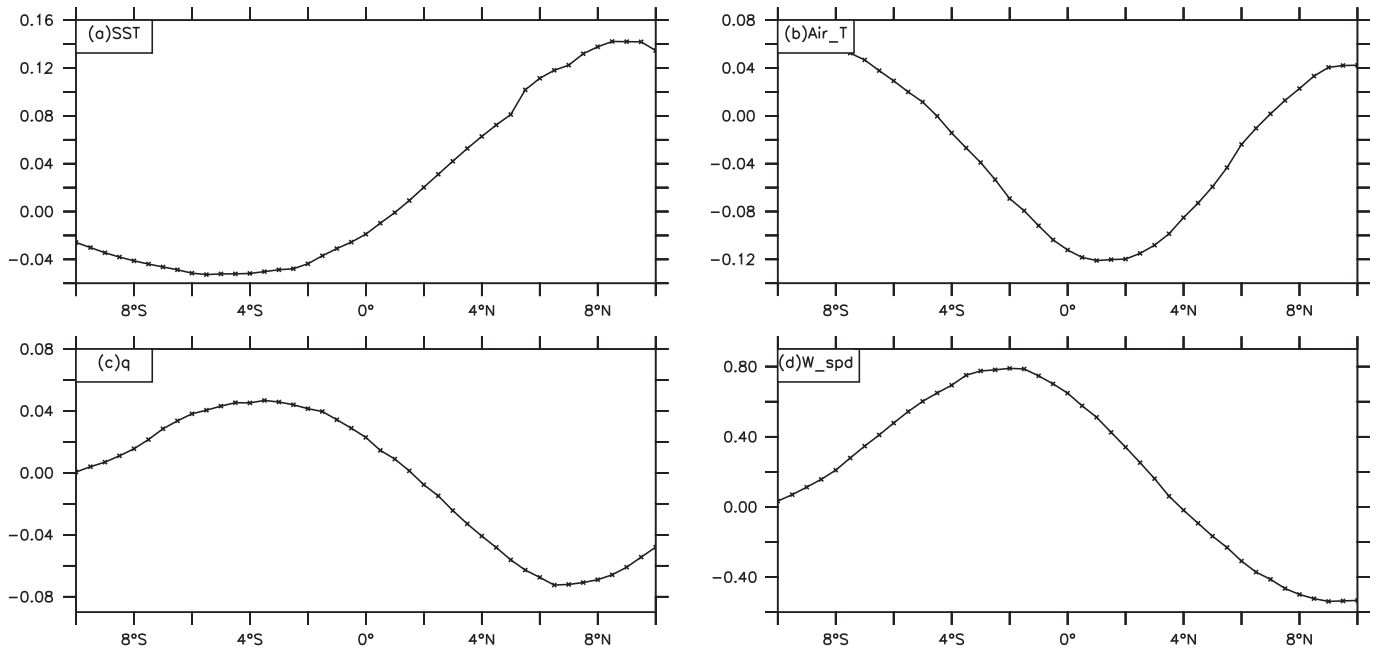

FIG. 11. Meridional distributions of anomalous (a) SST $\left({ }^{\circ} \mathrm{C}\right)$, (b) air temperature at $2 \mathrm{~m}(\mathrm{~K})$, (c) specific humidity

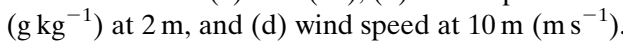



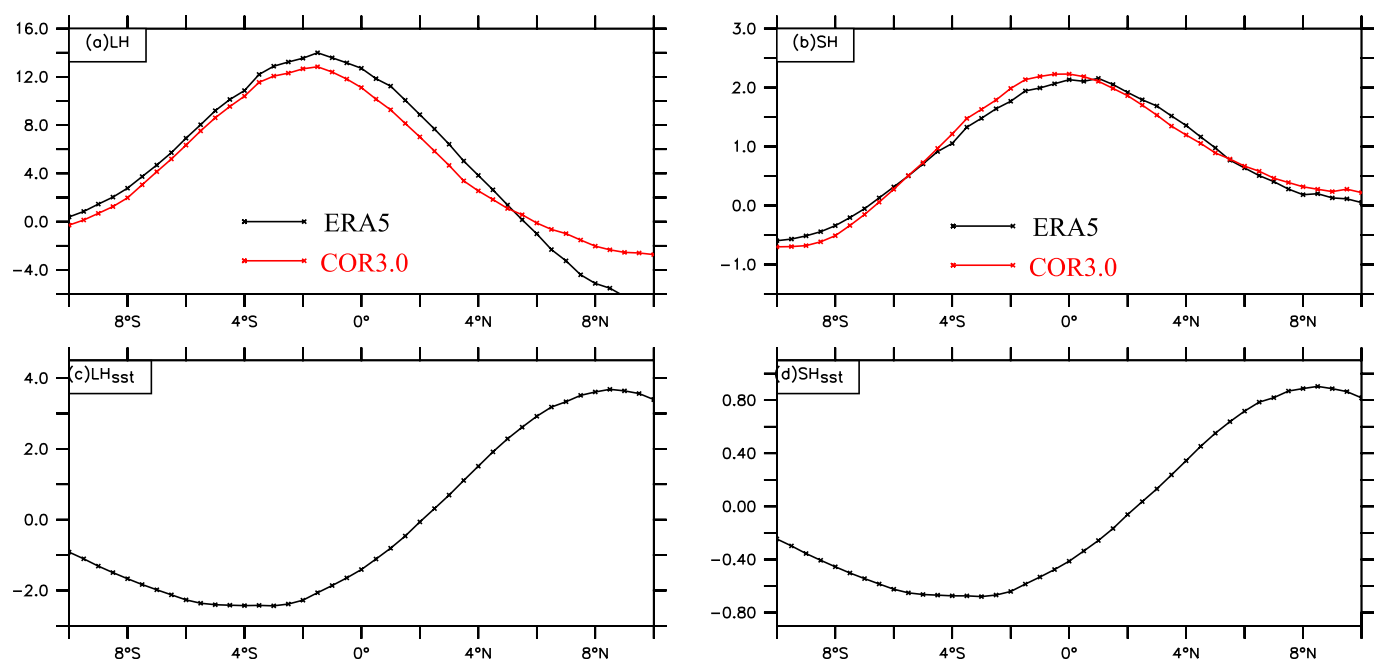

FIG. 12. Meridional distributions of (a) LH and (b) SH anomalies in ERA5 (black line) and COARE3.0 (red line), (c) SST-induced LH anomalies, and (d) SST-induced SH anomalies. The unit is $\mathrm{W} \mathrm{m}^{-2}$.

heat fluxes would be induced ahead of (behind) the convection center. Such a meridional distribution, in this sense, fits well with the column-integrated MSE recharge/ discharge associated with the development of the QBWO convection (Fig. 8a). In contrast to the SST, the air temperature exhibits negative anomalies in the active convection regions, and the minimum is slightly northward ahead of the convection center. Meanwhile, it is noted that the surface specific humidity displays negative (positive) anomalies to the north (south) of the convection center, which differs from the averaged specific humidity in the PBL (Fig. 5a). The maximum wind speed lags slightly southward relative to the convection center, and pronounced negative anomalies are found to the north of it. On the condition that the mean southwesterly is sustained (Fig. 7a), the above meridional pattern is easily understood; that is, to the south of the convection center, the total wind is strengthened due to the perturbation westerlies (Fig. 4b) and perturbation southerlies (Fig. 4c), while the opposite is true to the north of the convection center. Even when significant perturbations are observed in the above four surface parameters, their induced LH anomalies largely resemble the evolution of wind speed (Fig. 12a). Positive LH anomalies occupy most of the convective region, with a maximum at approximately $2^{\circ}$ latitude behind the convection center. The SH anomalies, in a similar manner, largely depend on the wind speed anomalies (Fig. 12b), although their magnitude is much smaller. Moreover, it is worth noting that the $\mathrm{LH}$ and SH anomalies based on the COARE3.0 algorithm (red line) approach the values derived from ERA5 (black line), giving us confidence to further examine SST feedback to the turbulent heat fluxes.
According to section 2c, SST-induced turbulent heat flux anomalies are calculated and illustrated in Figs. 12c,d. Both $\mathrm{LH}_{\text {sst }}$ and $\mathrm{SH}_{\mathrm{sst}}$ coincide with SST anomalies, recharging (discharging) the MSE in front (the rear) of the QBWO convection. For a quantitative evaluation, the distinct contrast in the MSE tendency between the recharge area (northern side) and discharge area (southern side) is $21.2 \%$ on account of SST-induced turbulent heat fluxes, wherein LH accounts for $16.9 \%$ and $\mathrm{SH}$ accounts for $4.3 \%$ (Fig. 13).

To be addressed here, the change in the surface turbulent heat fluxes is not the only way through which SST provides feedback to QBWO convection, and the above fraction is not the total amount of potential SST

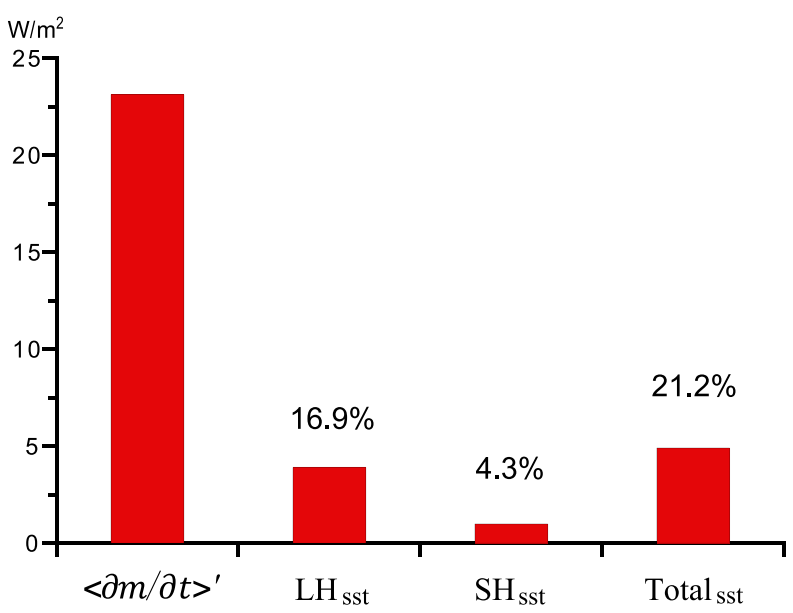

FIG. 13. Differences between the recharge and discharge area in the column-integrated MSE tendency, SST-induced LH anomalies, SST-induced SH anomalies, and SST-induced total turbulent heating anomalies $\left(\mathrm{W} \mathrm{m}^{-2}\right)$. Partial contributions of SST-induced anomalies to the column-integrated MSE tendency are shown. 
feedback. It has been shown that SST anomalies and their gradients can influence the propagation of 30-60day ISOs by driving PBL convergence (Hsu and Li 2012; Wang et al. 2018). This mechanism probably operates in the QBWO because the phase-leading PBL convergence was proved to be critical in the moisture asymmetry in the previous section; accordingly, an examination of the SST feedback in the mechanism is a task for future work. In fact, the above processes only describe the locally direct contribution from the SST, and an accurate assessment of ocean feedback to the atmosphere should also take indirect and cumulative effects into consideration, as suggested in Fu et al. (2018). Overall, the complex response of atmospheric convection to SST perturbations makes it difficult to diagnose the net effects of ocean feedbacks.

\section{Summary and discussion}

\section{a. Summary}

At the intraseasonal time scale, the 10-20-day QBWO and 30-60-day ISO are activated in the WNP, and both exhibit pronounced northward propagation during summer. Compared with extensive studies on the ISO, less attention has been paid to many fundamental dynamics of the QBWO. Based on newly released ERA5 and remote sensing data, this study investigates the northwardpropagating QBWO in the WNP by examining composite meridional structures.

The result indicates that the QBWO originates at the equatorial Pacific and propagates northwestward toward East Asia at a speed of approximately $1.7^{\circ}$ latitude per day. The composite meridional structures of the QBWO convection provide essential clues for the mechanism of this northward propagation. The vertical velocity, coinciding though its maximum with the convection center, exhibits a southward tilted structure as the height increases. In the rear of the convection, a striking ascending motion is induced in the upper troposphere due to stratiform heating, while in the front of the convection, a significant upward motion associated with the PBL shallow convective systems occurs in the lower troposphere. Due to the vertical shear of mean winds, barotropic vorticity anomalies are generated ahead of the convection center, and the related Ekman pumping further gives rise to meridional asymmetry in the PBL convergence. It is worth noting that the meridional contrast in the PBL moisture, with larger values north of the convection center, probably favors the northward propagation of the QBWO.

Details on the governing processes responsible for the meridional PBL moisture asymmetry are analyzed with the aid of moisture budget analysis. The result reveals that moisture convergence is the primary term, while meridional moisture advection is the secondary term contributing to the moisture asymmetry. Furthermore, the interactions between the QBWO perturbations and mean states are addressed to elucidate the physical processes. The moisture convergence term is predominantly attributed to the interaction between the QBWO divergence anomalies and mean moisture, obviously depending on the meridional PBL divergence asymmetry forced by barotropic vorticity anomalies. Moisture advections by the mean and perturbation meridional winds make almost equal contributions to the meridional advection term. The former depicts the steering effect of a mean southerly in the WNP, and the latter reflects the meridional contrast of anomalous wind in the presence of a mean northward moisture gradient.

There is a distinct meridional contrast in the MSE tendency associated with the QBWO convection. MSE recharges in front of and discharges in the rear of convection, promoting the northward propagation of the QBWO convective system. Column-integrated MSE budget analysis shows that the meridional MSE contrast is jointly contributed by the meridional and vertical MSE advection. The meridional MSE advection mainly depends on the moisture processes, with the largest such contribution coming from the PBL. The vertical MSE advection largely results from the advection of the mean MSE by the vertical velocity anomalies. Given that the mean MSE is minimized in the midtroposphere, the meridional difference in vertical velocity anomalies (Fig. 5b) would induce positive (negative) MSE advection ahead of (behind) the convection center. It further indicates that the upper-troposphere ascending motion related to stratiform heating in the rear of convection plays a major role.

The air-sea interaction involved in the QBWO life cycle may play an important role in the evolution of convective systems. On the basis of MSE budget analysis, the partial feedback from SST anomalies is quantified by examining their impacts on the surface turbulent heat fluxes. SST anomalies tend to enhance the surface turbulent heat fluxes ahead of the convention center and suppress them behind the convention center, inducing a similar meridional contrast as the column-integrated MSE tendency. Quantitatively, SST-induced turbulent heat fluxes contribute approximately $21 \%$ of the meridional contrast in the MSE tendency, with LH accounting for approximately $17 \%$ and $\mathrm{SH}$ accounting for approximately $4 \%$.

\section{b. Discussion}

The above summarizes the results on the meridional structures and northward-propagating mechanisms associated with the 10-20-day QBWO. At the same time, relevant analysis of the 30-60-day ISO over the WNP was 
conducted to make clear comparisons (figures not shown). Regardless of the discrepancy in peak periods, the QBWO shares many common characteristics with the ISO, such as the phase-leading structures in barotropic vorticity and PBL convergence, the second-baroclinic-mode vertical velocity, the PBL moisture dynamics and the MSE recharge/ discharge processes. Nevertheless, there are many differences between the two modes in the WNP. For example, the QBWO exhibits an evident northwestward evolution at approximately $1.7^{\circ}$ latitude per day, while the ISO displays generally northward movement at approximately $0.7^{\circ}$ latitude per day. The difference in the northward speed may closely relate to the MSE time tendency, since the meridional MSE recharge-discharge contrast associated with the ISO is less than half of the contrast in the QBWO. Regarding the vertical MSE advection, the upper-troposphere ascending motion related to the rearconvection stratiform cloud plays a major role in the QBWO, while the lower-troposphere ascending motion associated with the front-convection shallow convective systems is the dominant factor in the ISO. Additionally, the SST-induced turbulent heat fluxes account for approximately $20 \%$ of the QBWO MSE tendency; in contrast, they account for more than $40 \%$ of the ISO MSE tendency, suggesting a stronger air-sea coupling in the later mode.

Since the essential physics involved in the QBWO mostly depend on the interactions between the perturbations and mean states, the present results are not strictly representative of other basins or of other seasons. Indeed, the distinctions of the QBWO occurring in different monsoon stages and different decadal states have already been noted (e.g., Wang et al. 2016; Xu et al. 2017; C. Li et al. 2018). Moreover, it is suggested that a better simulation of mean states would be helpful to produce better QBWOs in models.

Acknowledgments. This work was jointly supported by National Key R\&D Program of China (2018YFC1505802), Basic Scientific Fund for National Public Research Institutes of China (2020S01), Global Change and Air-Sea Interaction Program (GASI-IPOVAI-03 and GASIIPOVAI-02), China Ocean Mineral Resources Research and Development Association Program (DY135-E2-303), National Science Foundation of China (41976020 and 41676020), and AoShan Talents Cultivation Program supported by Qingdao National Laboratory for Marine Science and Technology (2017ASTCP-OS01).

\section{REFERENCES}

Adames, Á. F., and J. M. Wallace, 2015: Three-dimensional structure and evolution of the moisture field in the MJO. J. Atmos. Sci., 72, 3733-3754, https://doi.org/10.1175/JAS-D-15-0003.1.
— , and D. Kim, 2016: The MJO as a dispersive, convectively coupled moisture wave: Theory and observations. J. Atmos. Sci., 73, 913-941, https://doi.org/10.1175/JAS-D-15-0170.1.

Bellon, G., and A. H. Sobel, 2008: Instability of the axisymmetric monsoon flow and intraseasonal oscillation. J. Geophys. Res., 113, D07108, https://doi.org/10.1029/2007JD009291.

Benedict, J. J., and D. A. Randall, 2007: Observed characteristics of the MJO relative to maximum rainfall. J. Atmos. Sci., 64, 2332-2354, https://doi.org/10.1175/JAS3968.1.

Chatterjee, P., and B. N. Goswami, 2004: Structure, genesis and scale selection of the tropical quasi-biweekly mode. Quart. J. Roy. Meteor. Soc., 130, 1171-1194, https://doi.org/10.1256/ qj.03.133.

Chen, G., and C. Sui, 2010: Characteristics and origin of quasibiweekly oscillation over the western North Pacific during boreal summer. J. Geophys. Res., 115, D14113, https://doi.org/ 10.1029/2009JD013389.

Chen, T., and J. Chen, 1993: The 10-20-day mode of the 1979 Indian monsoon: Its relation with the time variation of monsoon rainfall. Mon. Wea. Rev., 121, 2465-2482, https://doi.org/ 10.1175/1520-0493(1993)121<2465:TDMOTI>2.0.CO;2.

— , and — 1995: An observational study of the South China Sea monsoon during the 1979 summer: Onset and life cycle. Mon. Wea. Rev., 123, 2295-2318, https://doi.org/10.1175/15200493(1995)123<2295:AOSOTS>2.0.CO;2.

— monsoon depressions and their westward-propagating predecessors. Mon. Wea. Rev., 127, 1005-1020, https://doi.org/10.1175/ 1520-0493(1999)127<1005:IAIVIM>2.0.CO;2.

Cui, J., L. Wang, T. Li, and B. Wu, 2020: Can reanalysis products with only surface variables assimilated capture MaddenJulian Oscillation characteristics? Int. J. Climatol., 40, 12791293, https://doi.org/10.1002/joc.6270.

DeMott, C. A., J. J. Benedict, N. P. Klingaman, S. J. Woolnough, and D. A. Randall, 2016: Diagnosing ocean feedbacks to the MJO: SST-modulated surface fluxes and the moist static energy budget. J. Geophys. Res. Atmos., 121, 8350-8373, https:// doi.org/10.1002/2016JD025098.

Duvel, J. P., R. Roca, and J. Vialard, 2004: Ocean mixed layer temperature variations induced by intraseasonal convective perturbations over the Indian Ocean. J. Atmos. Sci., 61, 1004-1023, https://doi.org/10.1175/1520-0469(2004)061<1004: OMLTVI $>2.0 . \mathrm{CO} ; 2$.

Fairall, C. W., E. F. Bradley, J. E. Hare, A. A. Grachev, and J. B. Edson, 2003: Bulk parameterization of air-sea fluxes: Updates and verification for the COARE algorithm. J. Climate, 16, 571-591, https:// doi.org/10.1175/1520-0442(2003)016<0571:BPOASF > 2.0.CO;2.

Fu, X., B. Wang, and L. Tao, 2006: Satellite data reveal the 3-D moisture structure of tropical intraseasonal oscillation and its coupling with underlying ocean. Geophys. Res. Lett., 33, L03705, https://doi.org/10.1029/2005GL025074.

_ W. Wang, Y. Zhu, H. L. Ren, X. Jia, and T. Shinoda, 2018: Impacts of different cumulus schemes on the pathways through which SST provides feedback to the Madden-Julian oscillation. J. Climate, 31, 5559-5579, https://doi.org/10.1175/JCLI-D-17-0432.1.

Gao, M., J. Yang, B. Wang, S. Zhou, D. Gong, and S.-J. Kim, 2018: How are heat waves over Yangtze River valley associated with atmospheric quasi-biweekly oscillation? Climate Dyn., 51, 4421-4437, https://doi.org/10.1007/s00382-017-3526-z.

Gao, Y., N. P. Klingaman, C. A. DeMott, and P.-C. Hsu, 2018: Diagnosing ocean feedbacks to the BSISO: SST-modulated surface fluxes and the moist static energy budget. J. Geophys. Res. Atmos., 124, 146-170, https://doi.org/10.1029/2018JD029303. 
Halkides, D. J., D. E. Waliser, T. Lee, D. Menemenlis, and B. Guan, 2015: Quantifying the processes controlling intraseasonal mixed-layer temperature variability in the tropical Indian Ocean. J. Geophys. Res. Oceans, 120, 692-715, https:// doi.org/10.1002/2014JC010139.

Hendon, H. H., and M. L. Salby, 1994: The life cycle of the Madden-Julian Oscillation. J. Atmos. Sci., 51, 2225-2237, https://doi.org/10.1175/1520-0469(1994)051<2225:TLCOTM> 2.0.CO;2.

Hersbach, H., and D. Dee, 2016: ERA5 reanalysis is in production. ECMWF Newsletter, No. 147, ECMWF, Reading, United Kingdom, 7, http://www.ecmwf.int/sites/default/files/elibrary/ 2016/16299-newsletter-no147-spring-2016.pdf.

Hsu, P., and T. Li, 2012: Role of the boundary layer moisture asymmetry in causing the eastward propagation of the MaddenJulian oscillation. J. Climate, 25, 4914-4931, https://doi.org/ 10.1175/JCLI-D-11-00310.1.

,$- \ldots$, and H. Murakami, 2014: Moisture asymmetry and MJO eastward propagation in an aquaplanet general circulation model. J. Climate, 27, 8747-8760, https://doi.org/10.1175/JCLID-14-00148.1.

Hung, M.-P., J.-L. Lin, W. Wang, D. Kim, T. Shinoda, and S. J. Weaver, 2013: MJO and convectively coupled equatorial waves simulated by CMIP5 climate models. J. Climate, 26, 6185-6214, https://doi.org/10.1175/JCLI-D-12-00541.1.

Jia, X., and S. Yang, 2013: Impact of the quasi-biweekly oscillation over the western North Pacific on East Asian subtropical monsoon during early summer. J. Geophys. Res. Atmos., 118, 4421-4434, https://doi.org/10.1002/JGRD.50422.

Jiang, X., 2017: Key processes for the eastward propagation of the Madden-Julian Oscillation based on multimodel simulations. J. Geophys. Res. Atmos., 122, 755-770, https://doi.org/10.1002/ 2016JD025955.

_ - T. Li, and B. Wang, 2004: Structures and mechanisms of the northward propagating boreal summer intraseasonal oscillation. J. Climate, 17, 1022-1039, https://doi.org/10.1175/15200442(2004)017<1022:SAMOTN>2.0.CO;2.

Kikuchi, K., and B. Wang, 2009: Global perspective of the quasibiweekly oscillation. J. Climate, 22, 1340-1359, https://doi.org/ 10.1175/2008JCLI2368.1.

Kim, D., J. Kug, and A. H. Sobel, 2014: Propagating versus nonpropagating Madden-Julian oscillation events. J. Climate, 27, 111-125, https://doi.org/10.1175/JCLI-D-13-00084.1.

Krishnamurti, T. N., and P. Ardanuy, 1980: The 10 to 20-day westward propagating mode and "breaks in the monsoons." Tellus, 32, 15-26, https://doi.org/10.3402/tellusa.v32i1.10476.

—, P. K. Jayakumar, J. Sheng, N. Surgi, and A. Kumar, 1985: Divergent circulations on the 30 to 50 day time scale. J. Atmos. Sci., 42, 364-375, https://doi.org/10.1175/1520-0469(1985)042<0364: DCOTTD $>2.0 . \mathrm{CO} ; 2$.

Kummerow, C., and Coauthors, 2000: The status of the Tropical Rainfall Measuring Mission (TRMM) after two years in orbit. J. Appl. Meteor., 39, 1965-1982, https://doi.org/10.1175/15200450(2001)040<1965:TSOTTR > 2.0.CO;2.

Lau, K. M., and L. Peng, 1987: Origin of low-frequency (intraseasonal) oscillations in the tropical atmosphere. Part I: Basic theory. J. Atmos. Sci., 44, 950-972, https://doi.org/10.1175/ 1520-0469(1987)044<0950:OOLFOI >2.0.CO;2.

_ , and C. H. Sui, 1997: Mechanisms of short-term sea surface temperature regulation: Observations during TOGA COARE. J. Climate, 10, 465-472, https://doi.org/10.1175/1520-0442(1997) $010<0465$ :MOSTSS $>2.0 . \mathrm{CO} ; 2$.
Li, C., T. Li, and B. Zheng, 2018: Characteristic interdecadal change of quasi-biweekly and intraseasonal oscillations of summer convection over the South China Sea and the Western Pacific. Dyn. Atmos. Oceans, 83, 41-52, https://doi.org/10.1016/j.dynatmoce.2018.05.006. 1985: Actions of summer monsoon troughs (ridges) and tropical cyclones and the moving CISK mode. Sci. Sin., 28B, 1197-1206.

$\longrightarrow$ X. Jia, J. Ling, W. Zhou, and C. Zhang, 2009: Sensitivity of MJO simulations to diabatic heating profiles. Climate Dyn., 32, 167-187, https://doi.org/10.1007/s00382-008-0455-x.

Li, T., 1997: Air-sea interactions of relevance to the ITCZ: Analysis of coupled instabilities and experiments in a hybrid coupled GCM. J. Atmos. Sci., 54, 134-147, https://doi.org/ 10.1175/1520-0469(1997)054<0134:ASIORT >2.0.CO;2.

— and B. Wang, 2005: A review on the western North Pacific monsoon: Synoptic-to-interannual variabilities. Terr. Atmos. Oceanic Sci., 16, 285-314, https://doi.org/10.3319/TAO.2005.16.2.285(A).

_ , L. Wang, M. Peng, B. Wang, C. Zhang, W. Lau, and H. C. Kuo, 2018: A paper on the tropical intraseasonal oscillation published in 1963 in a Chinese journal. Bull. Amer. Meteor. Soc., 99, 17651779, https://doi.org/10.1175/BAMS-D-17-0216.1.

Liu, F., and B. Wang, 2014: A mechanism for explaining the maximum intraseasonal oscillation center over the western North Pacific. J. Climate, 27, 958-968, https://doi.org/10.1175/ JCLI-D-12-00797.1.

Liu, H., J. Yang, D. Zhang, and B. Wang, 2014: Roles of synoptic to quasi-biweekly disturbances in generating the summer 2003 heavy rainfall in East China. Mon. Wea. Rev., 142, 886-904, https://doi.org/10.1175/MWR-D-13-00055.1.

Madden, R. A., and P. R. Julian, 1971: Detection of a 40-50 day oscillation in the zonal wind in the tropical Pacific. J. Atmos. Sci., 28, 702-708, https://doi.org/10.1175/1520-0469(1971)028<0702: DOADOI $>2.0 . \mathrm{CO} ; 2$

Majda, A. J., and S. N. Stechmann, 2009: The skeleton of tropical intraseasonal oscillations. Proc. Natl. Acad. Sci. USA, 106, 8417-8422, https://doi.org/10.1073/pnas.0903367106.

Maloney, E. D., 2009: The moist static energy budget of a composite tropical intraseasonal oscillation in a climate model. J. Climate, 22, 711-729, https://doi.org/10.1175/2008JCLI2542.1.

— , and D. L. Hartmann, 1998: Frictional moisture convergence in a composite life cycle of the Madden-Julian oscillation. J. Climate, 11, 2387-2403, https://doi.org/10.1175/1520-0442(1998)011<2387: FMCIAC $>2.0 . \mathrm{CO} ; 2$

, and A. H. Sobel, 2004: Surface fluxes and ocean coupling in the tropical intraseasonal oscillation. J. Climate, 17, 43684386, https://doi.org/10.1175/JCLI-3212.1.

Mao, J., and J. C. L. Chan, 2005: Intraseasonal variability of the South China Sea summer monsoon. J. Climate, 18, 2388-2402, https://doi.org/10.1175/JCLI3395.1.

Martin, M., and Coauthors, 2012: Group for High Resolution Sea Surface Temperature (GHRSST) analysis fields inter-comparisons. Part I: A GHRSST multi-product ensemble (GMPE). Deep-Sea Res. II, 77-80, 21-30, https://doi.org/10.1016/j.dsr2.2012.04.013.

Neelin, J. D., and I. M. Held, 1987: Modeling tropical convergence based on the moist static energy budget. Mon. Wea. Rev., 115, 3-12, https://doi.org/10.1175/1520-0493(1987) 115<0003:MTCBOT>2.0.CO;2.

Numaguti, A., 1995: Characteristics of 4-to-20-day-period disturbances observed in the equatorial Pacific during the TOGA COARE IOP. J. Meteor. Soc. Japan Ser. II, 73, 353-377, https://doi.org/10.2151/JMSJ1965.73.2B_353.

Raymond, D. J., and Ž. Fuchs, 2009: Moisture modes and the Madden-Julian Oscillation. J. Climate, 22, 3031-3046, https:// doi.org/10.1175/2008JCLI2739.1. 
Shi, Y., Y. Du, Z. Chen, and C. Wang, 2019: Impact of the quasibiweekly oscillation on the super typhoon tracks in winter over the western North Pacific. Climate Dyn., 53, 793-804, https:// doi.org/10.1007/s00382-019-04614-6.

Tao, L., X. Fu, and W. Lu, 2009: Moisture structure of the quasibiweekly mode revealed by AIRS in western Pacific. Adv. Atmos. Sci., 26, 513-522, https://doi.org/10.1007/s00376-009-0513-2.

Wang, B., 1988: Dynamics of tropical low-frequency waves: An analysis of the moist Kelvin waves. J. Atmos. Sci., 45, 2051-2065, https:// doi.org/10.1175/1520-0469(1988)045<2051:DOTLFW>2.0.CO;2.

, 1994: On the annual cycle in the tropical eastern central Pacific. J. Climate, 7, 1926-1942, https://doi.org/10.1175/15200442(1994)007<1926:OTACIT > 2.0.CO;2.

, and H. Rui, 1990: Synoptic climatology of transient tropical intraseasonal convection anomalies: 1975-1985. Meteor. Atmos. Phys., 44, 43-61, https://doi.org/10.1007/BF01026810.

__ and X. Xie, 1996: Low-frequency equatorial waves in vertically sheared zonal flow. Part I: Stable waves. J. Atmos. Sci, 53, 449-467, https:// doi.org/10.1175/1520-0469(1996)053<0449:LFEWIV>2.0.CO 2 .

— oscillation. J. Atmos. Sci., 54, 72-86, https://doi.org/10.1175/ 1520-0469(1997)054<0072:AMFTBS >2.0.CO;2.

Wang, L., and T. Li, 2020: Effect of vertical moist static energy advection on MJO eastward propagation: Sensitivity to analysis domain. Climate Dyn., 54, 2029-2039, https://doi.org/ 10.1007/s00382-019-05101-8.

, _ _ E. E. Maloney, and B. Wang, 2017: Fundamental causes of propagating and nonpropagating MJOs in MJOTF/GASS models. J. Climate, 30, 3743-3769, https://doi.org/10.1175/ JCLI-D-16-0765.1.

Wang, T., X. Yang, J. Fang, X. Sun, and X. Ren, 2018: Role of airsea interaction in the 30-60-day boreal summer intraseasonal oscillation over the western North Pacific. J. Climate, 31, 16531680, https://doi.org/10.1175/JCLI-D-17-0109.1.

Wang, X., G. Chen, and R. Huang, 2016: Different characteristics of the quasi-biweekly oscillation over the South China Sea in two boreal summer stages. Theor. Appl. Climatol., 126, 1-13, https://doi.org/10.1007/s00704-015-1550-7.

Weller, R. A., and S. P. Anderson, 1996: Surface meteorology and air-sea fluxes in the western equatorial Pacific warm pool during the TOGA Coupled Ocean-Atmosphere Response Experiment. J. Climate, 9, 1959-1990, https://doi.org/10.1175/1520-0442(1996) 009<1959:SMAASF $>2.0$. CO;2.

Xie, X., and B. Wang, 1996: Low-frequency equatorial waves in vertically sheared zonal flow. Part II: Unstable waves. J. Atmos. Sci., 53, 3589-3605, https://doi.org/10.1175/1520-0469(1996)053<3589: LFEWIV $>2.0 . \mathrm{CO} ; 2$.

Xie, Y. B., S. J. Chen, I. L. Zhang, and Y. L. Huang, 1963: A preliminary statistic and synoptic study about the basic currents over southeastern Asia and the initiation of typhoon (in Chinese). Acta Meteor. Sin., 33, 206-217.

Xu, Z., T. Li, and K. Fan, 2017: The weakened intensity of the atmospheric quasi-biweekly oscillation over the western North Pacific during late summer around the late 1990s. J. Climate, 30, 9807-9826, https://doi.org/10.1175/JCLI-D16-0759.1.

Yanai, M., S. Esbensen, and J. Chu, 1973: Determination of bulk properties of tropical cloud clusters from large-scale heat and moisture budgets. J. Atmos. Sci., 30, 611-627, https://doi.org/ 10.1175/1520-0469(1973)030<0611:DOBPOT > 2.0.CO;2.

Ye, K., and R. Wu, 2015: Contrast of local air-sea relationships between 10-20-day and 30-60-day intraseasonal oscillations during May-September over the South China Sea and western North Pacific. Climate Dyn., 45, 3441-3459, https://doi.org/ 10.1007/s00382-015-2549-6.

Zhang, C., 2013: Madden-Julian oscillation: Bridging weather and climate. Bull. Amer. Meteor. Soc., 94, 1849-1870, https:// doi.org/10.1175/BAMS-D-12-00026.1.

Zhou, H., P. Hsu, and Y. Qian, 2018: Close linkage between quasibiweekly oscillation and tropical cyclone intensification over the western North Pacific. Atmos. Sci. Lett., 19, e826, https:// doi.org/10.1002/asl.826. 